\title{
Comparative study of Rosuvastatin with Atorvastatin in Ischaemic heart disease patients
}

\author{
${ }^{1}$ Dr.V.V.Padmavathi, ${ }^{2}$ Dr Chandrakala Kambar, ${ }^{3}$ Dr.Zaheda bano, ${ }^{4}$ Dr.Sankar \\ Kurli, ${ }^{5}$ Dr.G.Eswar, ${ }^{6}$ Dr. P.Ramesh babu \\ ${ }^{I}$ Dept.of.Pharmacology, ACSR Govt. Medical College Nellore \\ ${ }^{2}$ Dept.of.Pharmacology, Siddhartha MedicalCollege Vijayawada \\ ${ }^{3}$ Dept.of.Pharmacology, Guntur Medical College Guntur \\ ${ }^{4}$ Dept.of.Pharmacology, Siddhartha MedicalCollege Vijayawada \\ ${ }^{5}$ Dept. of Medicine, Siddhartha Medical College, Vijayawada \\ ${ }^{6}$ Citicardiac Research Centre, Dr.Ramesh hospitals, Vijayawada
}

\begin{abstract}
:
Objectives: The study was undertaken to compare the effect of Rosuvastatin with Atorvastatin on Plasma LDL Cholesterol and Total Cholesterol in Post-Myocardial Infarction and Unstable angina patients.

Methods: All patients were aged 30-70 years with a previous history of Acute Myocardial Infarction or Unstable Angina were randomly selected. 80 patients were recruited in the present study. 40 patients were on Rosuvastatin $10 \mathrm{mg}$. per day oral and the other 40 patients were on Atorvastatin $10 \mathrm{mg}$ per day oral. The study comprises of at least six months for each patient. Lipid profile was done before and after treatment.

Results: Eventhough both Rosuvastatin $10 \mathrm{mg}$ per day and Atorvastatin $10 \mathrm{mg}$ per day produced reduction in total cholesterol $(p<0.001)$ significantly, Rosuvastatin produced reduction in LDL levels $(p<0.001)$ more significantly than Atorvastatin $10 \mathrm{mg}$ per day.

Conclusion: Rosuvastatin produced greater reduction in LDL-C level than Atorvastatin.

Key words: Atorvastatin, LDL-C-Low Density lipoprotein Cholesterol, Rosuvastatin, TC-Total Cholesterol.
\end{abstract}

\section{Introduction}

Hyperlipidemia is a major cause of Atherosclerosis and its associated conditions such as coronary artery disease, Ischemic cerebro vascular disease and peripheral vascular diseases. World Health Organisation(WHO) has drawn attention to the fact that Coronary Heart Disease(CHD) as our modern EPIDEMIC i.e a disease that affects population not an Unavoidable attribute of ageing. Coronary Heart Disease is the commonest cause of cardiovascular disability and death ${ }^{1}$. In India it is fast becoming major killer. It is estimated that there are more than 30 million patients with Coronary Heart Disease in India ${ }^{2}$.

Compared to Europeans, Americans \& other Asians the prevalence, incidence, hospitalization and mortality from Coronary Heart Disease in India is 2-4 fold higher at all ages and 5-10 fold higher in those 40 years of age. Indians are unique in having an atherogenic lipid profile \& Lipoprotein (a).

The treatment of Hyperlipidemia in Coronary Heart Disease is of two types.

1. Primary Prevention is to treat Hyperlipidemias in a patient who is prone to develop Coronary Heart Disease.

2. Secondary prevention is to treat patients who already have the Coronary Heart Disease.

The drug treatment of Hyperlipidemias includes:

Fibric Acid derivatives, Cholestyramine Resin, 3-hydroxy 3-methyl glutaryl co enzyme-A(HMG Co-A) reductase inhibitors (statins), estrogens, Probucal, Fibre, Gugulipid, Nicotinic Acid, Selective estrogen receptor modulators.

Now-a-days, Coronary Heart Disease is one of the major cause of death and hyperlipidemias are one of the main cause of Coronary Heart Disease. Among all drugs the statins are widely used in the treatment of hyperlipidemias and to decrease the Coronary Heart Disease.

The broad range of significant clinical benefits of statin therapy include a decrease in major coronary events, coronary revascularization, stroke and Transient Ischaemic Attack, death due to CHD and total mortality. Based on this we undertook this study to compare the efficacy of Rosuvastatin and Atorvastatin. As there are many patients having CHD this study has been undertaken, i.e.the treatment of Hyperlipidemia in CHD patients. 
The present study was conducted to

\section{Aims \& Objectives}

1. Compare the safety and efficacy of Rosuvastatin and Atorvastatin in reducing cardio vascular events in patients with coronary artery disease and elevated lipid levels.

2. Compare the efficacy of equivalent doses of Rosuvastatin and Atorvastatinin lowering LDL $-\mathrm{C}$ levels.

3. Compare the cost effectiveness of Rosuvastatin and Atorvastatin therapy.

\section{Patients And Methods}

This was a prospective and comparative study, performed in 100 patients attending the cardiology and medicine outpatient department, Govt.General Hospital, Vijayawada. All patients men and women aged 30-70 Years with a previous history of Acute Myocardial infarction or Unstable angina $>3$ months but $<20$ months were selected. This study was conducted on patients with lipid levels in the range of Total Cholesterol $\leq 240$ $\mathrm{mg} / \mathrm{dl}$; Triglycerides $<350 \mathrm{mg} / \mathrm{dl}$, LDL-C $>100 \mathrm{mg} / \mathrm{dl}$ were selected for the study. Before starting the study, the Ethical committee approved the protocol. Written and informed consent was obtained from each patient in local language.

Initially 100 patients were recruited into the study who met inclusion and exclusion criteria. Of these only 80 patients attended the outpatient department regularly till the end of the study.

These patients were selected and placed into two groups. One group was given Atorvastatin $10 \mathrm{mg}$ once daily, another group was given Rosuvastatin $10 \mathrm{mg}$ once daily, during the whole period of the study.

3.1 Inclusion criteria

- Age 30-70 years

- Sex: Male \& Female

- Not on statins for more than 4 week

- Low Density Lipoprotein-Cholesterol $>100 \mathrm{mg} / \mathrm{dl}$

- Serum creatinine $<1.2 \mathrm{mg} / \mathrm{dl}$

- Normal liver function test
3.2 Exclusion criteria

- Any acute illness

- Congestive heart failure

- Renal Failure

- Hepatic dysfunction

- Pregnancy and Lactation

- Diabetes Mellitus

- Thyroid

- Alcoholism

Before starting the study, the risk factors like smoking, hypertension, $\mathrm{H} / \mathrm{o}$ of Unstable Angina (USA) and H/o Myocardial Infarction (MI) were noted for each patient. Among the 80 patients in the study 59 patients had previous Ml (30 patients in Atorvastation group and 29 patients in Rosuvastatin group), 21 patients had unstable angina (10 patients in Atorvastatin group and 11 patients in Rosuvastatin group).

Among the 80 patients, 41 patients were hypertensives (20 in Atorvastatin group and 21 in Rosuvastatin Group), 31 patients were smokers (12 in Atorvastatin Group and 19 in Rosuvastatin Group). All patients under went routine clinical examinations encompassing routine laboratory tests like $\mathrm{Hb} \%$, blood sugar, blood urea, serum creatinine, lipid profile and liver function tests.

Among the 80 patients, 40 patients were given Atorvastatin $10 \mathrm{mg} /$ day and rest of the 40 patients Rosuvastatin $10 \mathrm{mg} /$ day.

The Food and Drug Administratiomn(FDA) approved starting dose of Rosuvastatin $10 \mathrm{mg} / \mathrm{once}$ daily and Atorvastatin $10 \mathrm{mg} /$ once daily was used during the whole period of the study. The drug doses were selected in order to achieve the target goal. The target goal is LDL - C levels $<100 \mathrm{mg} / \mathrm{dl}$ for patients with CHD, according to the 2001 NCEP guide lines. The same was the target goal for the present study.

The laboratory investigations performed initially were $\mathrm{Hb} \%$, Blood sugar, Blood urea, Serum creatinine, Serum bilirubin and lipid profile (Total cholesterol, Triglycerides, LDL - C, HDL -C). The ECG was taken, Echo cardiography records of the patients done at the time of discharge from the previous hospitalization were checked for ventricular dysfunction.

The patients were advised to come for follow up at least once in a month. At every follow-up the patients were asked about the occurrence, if any, of anginal episodes they suffered and their frequency, from the time of the last follow up. The patients were also asked for any other complaints, especially unexplained muscle weakness and muscle pain, noted during the treatment period.

The lipid profile was once again done after six months of follow up in all the patients.

After 6 months of treatment period, all investigations were repeated. Results were tabulated.

3.3. Test procedure for lipid profile: $[3,4,5,6]$

3.3.1. Total cholesterol: Chod/pod -phospho-tungstate method. Normal values: $130-250 \mathrm{mg} / \mathrm{dl}$

3.3.2. Triglycerides: (gpo - pod method with espas). Normal values: $150 \mathrm{mg} / \mathrm{dl}$

3.3.3. HDL cholesterol: (chod/pod - phosphotungstate method)

Normal values: 
In males $\quad: 30-70 \mathrm{mg} / \mathrm{dl}$

In females : 35-90 mg/dl

3.3.4. Low density lipoprotein cholesterol

$(\mathrm{LDL}-\mathrm{C})$ is calculated by the Friedewald equation

$\mathrm{LDL}-\mathrm{C}=\mathrm{TC}-(\mathrm{TG} / 5+\mathrm{HDL}-\mathrm{C})$

Where TC - Total Cholesterol

TG - Triglyceride

HDL-C - High Density lipoprotein cholesterol

1.4. Statistics. Comparision and significance were tested by paired' $t$ ' test and ' $P$ ' value was calculated.

\section{Results} lipid profile.

Both regimens were well tolerated but Rosuvastatin was more effective than atorvastatin in controlling

Among 80 patients, the incidence of CHD with hyperlipidemia was more at the age of 51-60 years. Among 80 patients, the incidence of CHD with hyperlipidemia was more in males as shown in Table no.1.

Table no.1: Demographic data

\begin{tabular}{|c|c|c|}
\hline Parameter & Atorvastatin & Rosuvastatin \\
\hline Age (\%) & & \\
$30-40$ & 0 & 0 \\
$41-50$ & 13 & 18 \\
$51-60$ & 17 & 20 \\
$61-70$ & 10 & 2 \\
& & \\
\hline Sex (\%) & & \\
Male & 80 & 87.5 \\
Female & 20 & 12.5 \\
\hline
\end{tabular}
no. 2 .

Percentage of patients with previous history of Hypertension, Smoking, MI and USA were given in Table

The total no. of patients with hypertension was 41(51.25\%). The number and \% of hypertensive patients were equal in both groups.

Table no.2: Percentage of patients with associated risk factors

\begin{tabular}{|l|l|l|}
\hline Parameter & Atorvastatin & Rosuvastatin \\
\hline Hypertension & $50 \%$ & $52.5 \%$ \\
\hline Smoking & $30 \%$ & $47.5 \%$ \\
\hline MI & $75 \%$ & $72.5 \%$ \\
\hline USA & $25 \%$ & $27.5 \%$ \\
\hline
\end{tabular}

In the Atorvastatin group a decrease of 5.5\% in T.C levels from that of baseline mean lipid level was seen. In the Rosuvastatin group a decrease of $11 \%$ in T.C level from that of base line mean T.C level was seen, the difference in reduction being 5.5\%. In the Atorvastatin group a decrease of 5.5\% in LDL.C levels from that of base line mean LDL-C level was seen. In the Rosuvastatin group a decrease of $14.55 \%$ in LDL.C levels from that of base line mean LDL-C levels was seen, the difference in reduction being $9.0 \%$.

In the Aorvastatin group there was $1.71 \%$ increase of HDL-C levels from that of mean base line HDL$\mathrm{C}$ levels was seen. In the Rosuvastatin group the increase of HDL-C levels was only $0.4 \%$ from that of mean base line HDL-C levels. The difference in increase was more in Atorvastatin group, the difference being $1.31 \%$. In the Atorvastatin group a decrease of $2.4 \%$ in T.G levels from that of mean base line T.G levels was seen. In the Rosuvastatin group a decrease of $15.86 \%$ in T.G levels from that of mean base line T.G levels was seen. The difference in reduction was more in Rosuvastatin group, reduction being $13.45 \%$

There was significant decrease in LDL $-\mathrm{C}$ level $(\mathrm{P}<0.001)$ in Rosuvastatin group. So, this study shows that Rosuvastatin $10 \mathrm{mg} /$ day is more effective than Atorvastatin $10 \mathrm{mg} /$ day in lowering LDL-C levels in patients with Hypercholesterolemia. 
Table no.3: Mean lipid levels in each group at the end of six months

\begin{tabular}{|l|c|c|c|c|c|c|}
\hline & $\begin{array}{c}\text { Base line } \\
(\mathrm{mg} / \mathrm{dl})\end{array}$ & $\begin{array}{c}\text { Atorvastatin } \\
(\mathrm{mg} / \mathrm{dl})\end{array}$ & $\%$ & $\begin{array}{c}\text { Base line } \\
(\mathrm{mg} / \mathrm{dl})\end{array}$ & Rosuvastatin & $\begin{array}{c}\% \\
(\mathrm{mg} / \mathrm{dl})\end{array}$ \\
\hline T.C & 205.4 & 193.95 & $5.5745 \%$ & 203.48 & 181.075 & $11.009 \%$ \\
\hline LDL-C & 130.975 & 123.775 & $5.49723 \%$ & 131.2 & 112.1 & $14.5579 \%$ \\
\hline HDL-C & 39.3 & 38.625 & $1.7176 \%$ & 40.475 & 40.3 & $0.4324 \%$ \\
\hline T.G & 164.6 & 160.63 & $2.414 \%$ & 166.6 & 140.18 & $15.861 \%$ \\
\hline
\end{tabular}

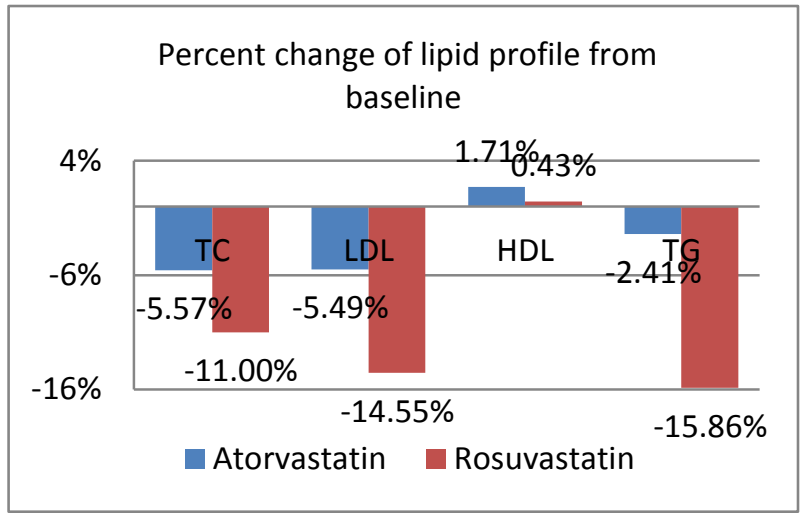

Fig no. 1: percent change from baseline

Table no.4: Incidence of coronary events in each group

\begin{tabular}{|l|c|c|l|}
\hline & USA & NON FATAL MI & TOTAL \\
\hline ATORVASTATIN & $2 / 40(5 \%)$ & $1 / 40(2.5 \%)$ & $3 / 40(7.7 \%)$ \\
\hline ROSUVASTATIN & $1 / 40(2.5 \%)$ & 0 & $1 / 40(2.5 \%)$ \\
\hline
\end{tabular}

Note: USA-Unstable angina, MI-Myocardial infarction

Both the drugs were well tolerated. No serious adverse effects were seen in both the groups. 10 patients (10/40) in Rosustatin group complained of abdominal distention and flatulence, 2 patients (5\%) in Atorvastatin group complained of constipation.

In Atorvastatin group, two patients had recurrent Unstable Angina and one patient had recurrent non fatal Ml, where as in Rosuvastatin group, one patient had recurrent unstable angina during six months followup.

\section{Discussion}

The HMG COA reductase inhibitiors (Statins) are powerful pharmacological agents for reducing LDL $\mathrm{C}$ levels and are effective in decreasing coronary artery disease. Their use in the treatment of hypercholesterolaemia has increased rapidly over the last few years.

The statins reduce overall mortality and secondary prevention of cardiovascular disease and reduce the incidence of CHD by 25 to $60 \% .{ }^{[7]}$ Clinical success of first generation HMG-CoA reductase inhibitors, has lead to the newer synthetic molecules being developed of which Rosuvostatin is one of the most recent. ${ }^{[8]}$

High level of LDL-C is an important risk factor for the development and progression of Coronary artery disease. $1 \%$ increase in serum cholesterol and $1.5 \%$ increase in serum LDL-C levels produce $2-3 \%$ increase in MI incidence as per the data given in Cardiology today Editorial, Nov-Dec, 1997. ${ }^{[2]}$

The $27^{\text {th }}$ Bethesda conference in matching the intensity of risk factor management with the hazards of coronary disease events offer clear guidelines for management of risk factors. ${ }^{[9]}$ It divides the risk factors into 4 classes:

Class I: Includes factors for which interventions have been proved to lower coronary artery disease risk. High HDL cholesterol is accorded class I status. The other risk factors included in this class are cigarette smoking, hypertension, high fat/cholesterol diet, left ventricular hypertrophy and thrombolytic factors.

Class II: Includes factors for which interventions are likely to lower coronary artery disease risk- Diabetes milletus, physical inactivity, low HDL cholesterol, high triglycerides, small dense LDL, obesity, postmenopausal women.

Class III: Factors that, if modified, might lower CAD risk- Psychological factors, lipoprotein (a), Homocysteine, oxidative stress, alcohol consumption. 
Class IV: Factors that cannot be modified or for which modification would be unlikely to lower coronary artery risk- Age, Male gender, low socio-economic status, Family H/o early onset Cardio Vascular Disease. Treatment by statins to reduce LDL-C levels has been shown to cause impressive reduction in the cardiovascular events.

The present study compares the efficacy, safety and the cost effectiveness of two HMG CO-A reductase inhibitors, Atorvastatin and Rosuvastatin in the secondary prevention of CAD. The total number of patients in the present study was 80 . Males constituted $83.75 \%$ of the total patients in the study and females constituted $16.25 \%$. In other studies, conducted on patients with CAD, the following observations were made.

Table no.5: Percentage of gender in various studies

\begin{tabular}{|l|c|c|c|c|c|}
\hline & $\mathrm{Cl}_{\text {jhala et al }}{ }^{[10]}$ & S study $^{[11]}$ & Care study $^{[12]}$ & Lipid study $^{[13]}$ & Present study \\
\hline Males & $61.20 \%$ & $81 \%$ & $86 \%$ & $83 \%$ & 83.75 \\
\hline Females & $38.80 \%$ & $19 \%$ & $14 \%$ & $17 \%$ & $16.25 \%$ \\
\hline
\end{tabular}

The highest incidence observed in the present study was in the age group of 51-60 years in both males and females. This is a decade earlier than that seen in western countries. This is due to life style changes.

Hypertension was the leading associated risk factor in the present study. It was seen in $51.25 \%(14 / 80)$ of the total number of patients in the study. The incidence of hypertension and smokers associated with hyperlipidemia in CAD patients as observed by various studies is shown in table no.6. and 7 respectively.

Table no.6: Incidence of hyperetension + hyperlipidemia in CAD patients

\begin{tabular}{|c|c|c|c|c|}
\hline Ch $_{\text {jhala et al }}{ }^{[10]}$ & $4 \mathrm{~S} \mathrm{study}^{[11]}$ & Care study $^{[12]}$ & Lipid study $^{[13]}$ & Present study \\
\hline $17.40 \%$ & $26 \%$ & $43 \%$ & $42 \%$ & $51.25 \%$ \\
\hline
\end{tabular}

Table no.7: Incidence of smokers in various studies

\begin{tabular}{|c|c|c|c|c|}
\hline Ch jhala et al ${ }^{[10]}$ & 4 S study $^{[11]}$ & Care study $^{[12]}$ & Lipid study $^{[3]}$ & Present study \\
\hline $19.90 \%$ & $26 \%$ & $21 \%$ & $10 \%$ & $38.75 \%$ \\
\hline
\end{tabular}

The lipid lowering effects of equivalent doses of Atorvastatin 10mg/day and Rosuvastatin 10mg/day were compared in the present study. It was observed that Atorvastatin reduced LDL-C levels by $5.5 \%(\mathrm{P}<0.01)$ and Rosuvastatin reduced LDL $-\mathrm{C}$ levels by $14.55 \%(\mathrm{P}<0.001)$

Table no.8: Reduced LDL-C levels in various studies

\begin{tabular}{|c|c|c|c|c|}
\hline & $\begin{array}{c}\text { Davidson m et al } \\
(12 \text { weeks })\end{array}$ & $\begin{array}{c}\text { Olsson ag et al }{ }^{[15]} \\
(52 \text { weeks })\end{array}$ & $\begin{array}{c}\text { Blasetto jw et al } \\
(12 \text { weeks })\end{array}$ & $\begin{array}{c}\text { Present study } \\
(24 \text { weeks })\end{array}$ \\
\hline Atorvastatin 10mg/day & $35 \%$ & $44 \%$ & $36.40 \%$ & $5.50 \%$ \\
\hline Rosuvastatin 10mg/day & $43 \%$ & $53 \%$ & $46.70 \%$ & $14.55 \%$ \\
\hline P value & $<0.001$ & $<0.001$ & $<0.001$ & $<0.001$ \\
\hline
\end{tabular}

It was observed that \% increase in HDL-C was not very much significant. The results in the various studies are as follows.

Table no. 9: Increased HDL-C levels in various studies

\begin{tabular}{|c|c|c|c|c|}
\hline & $\begin{array}{l}\text { Davidson } \mathrm{m} \text { et } \\
\mathrm{al}^{[14]} \\
(12 \text { weeks })\end{array}$ & $\begin{array}{l}\text { Olsson ag et } \\
\mathrm{al}^{[15]} \\
(52 \text { weeks })\end{array}$ & $\begin{array}{l}\text { Blasetto jw et } \\
\mathrm{al}^{[16]} \\
(12 \text { weeks })\end{array}$ & $\begin{array}{l}\text { Present } \\
\text { study } \\
(24 \text { weeks })\end{array}$ \\
\hline $\begin{array}{l}\text { Atorvastatin } \\
10 \mathrm{mg} / \text { day }\end{array}$ & $8 \%$ & 1 & $5.50 \%$ & $1.70 \%$ \\
\hline $\begin{array}{l}\text { Rosuvastatin } \\
10 \mathrm{mg} / \text { day }\end{array}$ & $12 \%$ & $3 \%$ & $8.90 \%$ & $0.40 \%$ \\
\hline P value & $<0.05$ & $<0.05$ & $<0.05$ & $<0.5$ \\
\hline
\end{tabular}

In the present study, the results represent the $\%$ of difference from that of LDL-C levels with the base line levels of the study group itself. The base line mean lipid levels are TC $<205 \mathrm{mg} / \mathrm{dl}$, LDL-C $<131 \mathrm{mg} / \mathrm{dl}$, HDL-C $>40 \mathrm{mg} / \mathrm{dl}$ and $\mathrm{TG}<166 \mathrm{mg} / \mathrm{dl}$. Atorvastatin $10 \mathrm{mg} /$ day was found to decrease TC by $5.57 \%$, LDL-C levels by $5.5 \%$, TG levels by $2.4 \%$. HDL-C levels were found to be increased by $1.71 \%$ in the present study.

Rosuvastatin $10 \mathrm{mg} / \mathrm{d}$ was found to decrease total cholesterol levels by $11 \%$, LDL-C levels by $14.55 \%$ and triglycerides levels by $15.86 \%$. HDL-C levels were found to be increased by only $0.43 \%$ in the present study. Eventhough both Atorvastatin and Rosuvastatin reduced total cholesterol levels equally $(\mathrm{P}<0.001)$. The effect on LDL-C and HDL-C were different. The results were consistent with Olsson AG et al. [ ${ }^{15]}$

Rosuvastatin is more effective than atorvastatin in lowering the LDL-C levels in patients with hypercholesterolaemia. This was similar to the study of Davidson $\mathrm{M}$ et al., Comparison of Effects on Low 
Density Lipoprotein Cholesterol and High Density Lipoprotein Cholesterol with Rosuvastatin Versus Atorvastatin in patients with type lla or llb hypercholesterolemia. ${ }^{14}$

Rosuvastatin significantly improved the triglyceride levels in IHD patients than Atorvastatin. The results were similar to the study of Carswell et al. ${ }^{8}$ The effect of Rosuvastatin on HDL Cholesterol levels were different from the other studies. ${ }^{[14,15,16]}$

Both the drugs were well tolerated. No serious adverse effects were noted.

Total recurrent coronary events in this study were 4/80 (5\%). In the Atorvastatin group it was $3 / 40$ (7.7\%). In the Rosuvastatin group it was only one (1/40) i.e. (2.5\%). The results were similar to the study of Shepherd J et al. ${ }^{[17]}$

Because of the high cost of the drugs it was not possible to recruit large number of patients for longer duration in this trial. So, further studies using large number of patients are necessary to confirm these results.

\section{Summary and Conclusion}

Many epidemiological studies have established the relation between elevated serum levels of total cholesterol and specifically LDL-C in the development of CHD. In Secondary prevention of CAD lipid lowering is an essential part of comprehensive programme of risk factor modification. The statins are highly effective lipid-lowering agents. The use of statins in post-infarct patients with moderate to severe hypercholesterolaemia is increasing.

80 patients were recruited in the present study. The effects of Statins, Rosuvastatin $10 \mathrm{mg}$. per day and Atorvastatin $10 \mathrm{mg} / \mathrm{d}$ were compared in post myocardial infarct patients or in patients with previous history of unstable angina with mild to moderate hypercholesterolaemia. The study comprises of atleast 6 months study for each patient. Lipid profile estimation was done before and after treatment. During this 6 months period, patients were monitored for recurrent coronary events and other adverse effects.

Results were tabulated, comparison and significance were tested by paired student-t test and P-value was calculated. Results were shown graphically also. This study shows that LDL levels were reduced by the two statins to the target goal mentioned in NCEP guide lines.

Eventhough both Rosuvastatin $10 \mathrm{mg} / \mathrm{day}$ and Atorvastatin $10 \mathrm{mg} / \mathrm{d}$ produced reduction in total cholesterol levels $(\mathrm{P}<0.001)$ significantly, Rosuvastatin produced reduction in LDL-C levels $(\mathrm{P}<0.001)$ more significantly than Atorvastatin $10 \mathrm{mg} /$ day $(\mathrm{P}<0.01)$. Rosuvastatin $10 \mathrm{mg} / \mathrm{d}$ produced triglyceride reduction $(\mathrm{P}<0.01)$ more significantly than Atorvastatin $10 \mathrm{mg} / \mathrm{d}(\mathrm{P}<0.1)$. Rosuvastatin $10 \mathrm{mg} / \mathrm{day}$ has no significant increase in HDL-C levels when compared to Atorvastatin $(\mathrm{P}<0.1)$. Both the statins caused a decrease in coronary events. Rosuvastatin seems to have a greater decrease in the incidence of coronary events when compared to Atorvastatin. Both the statins had a good safety profile with few adverse effects. Atorvastatin being cheaper than Rosuvastatin Atorvastatin can be adviced to the patients.

In conclusion, the present study showed that Rosuvostatin $10 \mathrm{mg} / \mathrm{d}$ had better response in Lipid-profile regulation except increasing HDL-C levels in IHD patients than Atorvastatin $10 \mathrm{mg} / \mathrm{d}$.

The study was conducted for only a short period of time (six months). This was due to constraint of time. So, further and more extensive comparative evaluation of the effects of Rosuvastatin and Atorvastatin is needed.

\section{Acknowledgments}

Dr.Ramesh Multispeciality hospital,Vijayawada (City Cardiac Research Centre)

\section{References}

[1] Parks Text Book of Preventional and Social Medicine, $18^{\text {th }}$ Edition, Ch.6:286-287.

[2] Editorial, Cardiology Today: Nove-Dec 1997-Vol-1, Vol-2.

[3] Jacobe, N.J., Van Demark, P.J. (1960) Arch Biochem. Biophys. 88,250.

[4] Trinder, P (1960) Amn.Clin.Biochem., 6.24

[5] Bucolo G., David M.Clin. Chem 19,476 (1973)

[6] Werner M., Gabrielson D.G., Eastman G. Clin Chem 27, 268 (1981).

[7] Knoop RH. Durg treatment of lipid disorders, N Engl J Med 1999 Aug 12:341 (7): 498-511.

[8] Carswell Cl, Plosker GL, Jarvis B.Rosuvastatin. Drugs 2002:62(14):2075-2085.

[9] Enas, A., Cardiology Today, Jan - Feb. 1998; Vol-II, No.1.

[10] C.I.Jhala, V.A.Shah et al., Patterns of cardiac disorders \& Epidemiology of Coronary artery disease in Urban population of Ahmedabad, J Indian Med. Assoc. 1999, 97(6):237-240.

[11] Scandinavian Simvastatin Survival Study. Randomized trial of Cholesterol lowering in 4444 Patients with Coronaryheart disease, The Scandinavian Simvastain Survival Study (4S),Lancet 1994; 1383-89.

[12] Sacks FM, Pfefer MA et al, The Effect of Pravastatin on Coronary events after myocardial infarction in patients with average cholesterol levels. Cholesterol \& Recurrent Events Trail investigators (CARE). NEJM 1996; 335: 1001-1009.

[13] The long term Intervention with Pravastatin in Ischemic Disease (LIPID) Study Group. Prevention of Cardiovascular events \& death with Pravastatin in patients with Coronary heart disease \& a broad range of initial Cholesterol levels. NEJM 1998:339:134957.

[14] Davidson M. Comparison of Effects on Low Density Lipoprotein Cholesterol and High-Density Lipoprotein Cholesterol with Rosuvastatin Versus Atorvastatin in Patients with type II a or II b Hypercholesterolemia. Am J Cardiol 2002; 89:268-275. 
[15] Olsson AG et al. Effect of Rosuvastatin and atorvastatin compared over 52 weeks of treatment in patients with hypercholesterolemia. Am Heart J 2002; 144:1044-51

[16] Blasetto JW. Stein EA. Et al. Efficacy of rosuvastatin compared with other statins at selected starting doses in hypercholesterolemic patients and in special population groups. An J Cardiol. 2003 Mar 6;91 (5A):3C-10C; discussion 10C.

[17] Shepherd J, Hunninghake DB, et al. A review of safety profile of rosuvastatin in an international phase II/III clinical trial programme. Int J Clin Pract 2001, (suppl.124). 